\title{
ANALYSIS OF MOTOR VEHICLE SOURCES AND THEIR CONTRIBUTION TO AMBIENT HYDROCARBON DISTRIBUTIONS AT URBAN SITES IN TORONTO DURING THE SOUTHERN ONTARIO OXIDANTS STUDY
}

\author{
R. MCLAREN and D. L. SINGLETON \\ Institute for Environmental Research and Technology, National Research Council, Ottawa, Ont., \\ Canada K1A OR6 \\ and
}

J. Y. K. LAI, B. KHOUW, E. SINGER, Z. WU and H. NIKI

Centre for Atmospheric Chemistry and Department of Chemistry, York University, 4700 Keele St., North York, Ont., Canada

\begin{abstract}
Hydrocarbon distributions measured in the urban area of Toronto during the Southern Ontario Oxidants Study of 1992 are presented. Comparison is made to hydrocarbon distributions measured in other urban areas. Relative concentrations of olefins were found to be depleted aloft compared to the surface level measurements. Chemical mass balance modelling was used to apportion the measured hydrocarbon distributions at York University and other roadside sites to gasoline based sources. The most dominant contributing source was vehicle exhaust. The relative amount of unburned gasoline at York University was found to be significant in the summer, and higher than that observed there during the winter or at other roadside sites. The relative amount of evaporative emissions (gasoline vapour) apportioned by the CMB model at roadside sites was compared to evaporative emissions predicted by a mobile emission factor model, MOBILE5C. The percentage of gasoline based non-methane hydrocarbons (NMHC) apportioned to gasoline vapour by the CMB model was equivalent within error to the relative amount of evaporative NMHC predicted by the MOBILESC model for summer temperatures. For winter temperatures, the MOBILE5C model predicted significantly less evaporative emissions than that apportioned by the CMB model. An anthropogenic source of isoprene in the urban area has been proposed and tested. The inclusion of an isoprene flux in the exhaust source profile, consistent with that measured in the Auto/Oil Air Quality Improvement Research Program, results in calculated isoprene concentrations that are in agreement with observed concentrations at roadside sites and at York University in the winter. During summer, the combustion related isoprene can only account for a small fraction of the observed isoprene at downtown sites and at York University, at most $20 \%$.
\end{abstract}

Key word index: Anthropogenic emissions, chemical mass balance, gasoline, isoprene, mobile sources.

\section{INTRODUCTION}

The urban atmosphere can be characterized by the presence of many air contaminants including nitrogen oxides, hydrocarbons, carbon monoxide, aerosols and particulate matter. A characterization of hydrocarbons, in particular, is important for an assessment of: human exposure to air toxics (Dann and Wang, 1992), the reactive potential of the urban mixture with respect to ozone formation, and more recently for the verification of $\mathrm{HC}$ emission inventories that are ultimately used in air quality management plans and photochemical modelling (Harley et al., 1992).

The ozone formation process in the troposphere is known to involve photolytic reactions of nitrogen oxides, catalyzed by reactions of organic hydrocarbons (HCs) in the presence of sunlight (Chameides et al., 1992). Both anthropogenic and biogenic hydrocarbons are important in this respect. Hydrocarbons have differing reactive potentials with respect to ozone formation (Carter and Atkinson, 1989), and successful photochemical modelling requires that a reasonably accurate description of the source volatile organic compound (VOC) composition be included in the modelling inventory. Mobile sources in particular are known to contribute significantly to urban hydrocarbon and nitrogen oxide levels. For this reason, mobile sources have historically been at the focus of control strategies aimed at alleviating the ozone problem across North America (Calvert et al., 1993).

A recent report by the National Research Council in the United States has concluded that VOC emissions inventories are highly uncertain and may be 


\section{R. MCLAREN et al.}

severely underestimated (NRC, 1992). This underestimation may be partially responsible for the limited success of VOC control strategies across the U.S during the last two decades in solving the ground level ozone problem. The NRC conclusion was based upon several studies, including ambient measurement studies in urban areas that showed that VOCs and carbon monoxide are probably underestimated (Pierson et al., 1990; Fujita et al., 1992). An underestimation of VOCs and $\mathrm{CO}$ emitted by on-road mobile sources under real world conditions is likely, based upon several recent tunnel studies in the U.S. (Ingalls, 1989; Robinson et al., 1993). Since urban $\mathrm{NO}_{x}$, VOC and $\mathrm{CO}$ inventories are frequently dominated by on-road mobile sources, and since roadside mobile emissions are largely accounted for by the vehicle tailpipe, an underestimation of exhaust emissions by the mobile emissions factors models (see for example U.S. EPA, 1991 ) is suspected. Indeed, a recent photochemical modelling study of the Southern California Air Quality Study (SCAQS) (Harley et al., 1993) showed improved performance in the ozone and reactive hydrocarbon prediction when the on-road organic vehicle exhaust in the inventory was doubled as suggested by the SCAQS tunnel study (Ingalls, 1989). This result supports the assumption that hydrocarbon inventories are underestimated, but does not prove that the source of the underestimation is from vehicle exhaust. In another recent study (Harley et al., 1992), chemical mass balance (CMB) modelling was used to show that a significant amount of unburned gasoline is present in the Los Angeles ambient atmosphere, much more than can be accounted for by the official inventory for the region. The source of the unburned gasoline could not be identified although several sources were suggested including understated "hot soak" or fuel spillage emissions, or additional unburned fuel in vehicle exhaust, above and beyond that accounted for by Federal Test Procedure (FTP) based dynamometer testing. The issue of unburned gasoline is important since the unburned fuel is much more reactive with respect to ozone formation than its corresponding vapour.* Any misallocation of unburned gasoline to a gasoline vapor profile in a modelling inventory would result in an underestimation of predicted ozone.

Chemical mass balance modelling (Cass and McRae, 1983) can be used to estimate the contribution of emission sources to observed ambient pollutant concentrations measured at receptor sites. This type of modelling cannot be used to calculate absolute emission fluxes from those sources, rather it can be

\footnotetext{
*The "reactivity" of the summer gasoline and summe vapour profiles in Table 3 in this paper were calculated to be 3.36 and $1.93 \mathrm{~g} \mathrm{O}_{3} / \mathrm{g} \mathrm{HC}$, respectively at $20^{\circ} \mathrm{C}$ using maximum incremental reactivity factors (MIR) for hydrocarbons calculated by W. P. L. Carter (CARB, 1991). The unburned gasoline is $\sim 75 \%$ more reactive than the vapour using this measure.
}

used to calculate their relative contributions. This source-receptor modelling approach has been applied in a number of urban source apportionment studies with the intention of reconciling emissions inventories with ambient measurements (Aronian et al., 1989; Harley et al., 1992; Kenski et al., 1993). CMB modelling has also been applied specifically to the apportionment of mobile source VOCs to tailpipe and non-tailpipe sources from ambient air and tunnel samples (Gertler et al., 1993; Lin and Milford, 1993).

Speciated hydrocarbon measurements of atmospheric samples have been made at York University and at a number of other urban sites in and around the city since 1991. Analysis was carried out at these sites during the year previous to, and during the Southern Ontario Oxidants Study (SONTOS) in the summer of 1992. The SONTOS field measurement study was carried out in the urban and rural areas of Southern Ontario surrounding the city of Toronto. The purpose of this study was to help determine some of the factors leading to the production of high ozone levels in the Windsor to Quebec corridor. This region has been identified as one of the regions of concern in Canada where a significant fraction of the population is exposed to ozone levels thought to be detrimental to human health (CCME, 1990). The area of the SONTOS study is shown in Fig. 1, with a highlighting of the urban areas. The two rural sites, Hastings and Binbrook are downwind and upwind of Toronto, respectively, during usual atmospheric flow conditions associated with high ozone levels.

In this paper, hydrocarbon distributions measured during the 1991-1993 period at a number of sites in Toronto are presented. These distributions are compared to those measured in other urban areas. The CMB model was used to apportion gasoline based non-methane hydrocarbons (NMHC) to different sources. Gasoline based NMHC is meant to imply those hydrocarbons coming from emission sources related to the use of gasoline, on-road mobile sources being the most dominant source. In particular, we wished to assess the importance of unburned gasoline in ambient air, and to examine any seasonal variability. The paper also explores the presence of an anthropogenic source of isoprene in the urban area. Isoprene, a highly reactive and significant biogenic emission, is usually attributed only to emissions from vegetation.

\section{EXPERIMENTAL}

\section{Hydrocarbon speciation}

Grab samples at the different urban sites were collected in electropolished stainless steel canisters. Hydrocarbon analysis was done using capillary gas chromatography (GC) with flame ionization detection (FID). The details and performance of the analytical system have been published previously (Lai et al., 1993). In short, a two stage cyrotrapping unit (built in-house) was used for preconcentration and 


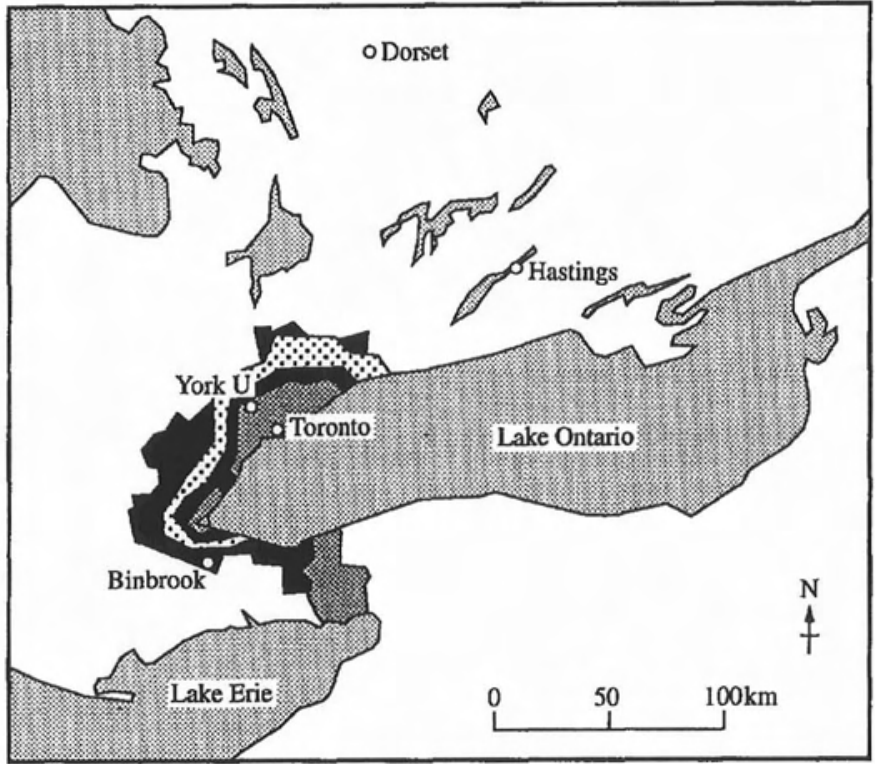

Fig. 1.

Table 1. Sampling sites for hydrocarbon speciation

\begin{tabular}{lllr}
\hline Sampling site & \multicolumn{1}{c}{ Site description } & \multicolumn{1}{c}{ Period of sampling } & No. samples \\
\hline Bay street & Roadside, urban driving & Summer, 1992 & 12 \\
Windsor Tunnel & Roadside, highway driving & Winter-spring, 1992 & 4 \\
Hwy 400 & Roadside, highway driving & Summer, 1992 & 7 \\
Hwy 401 & Roadside, highway driving & Winter, 1992 & 7 \\
CN Tower Base & Downtown urban area & Summer, 1991 & 9 \\
Queens' Park & Downtown urban area & Summer, 1991 & 7 \\
York University & City centre, suburban & July 1991-April 1993 & 344 \\
Aircraft & 600-800 m above Toronto & Summer 1992 & 7 \\
\hline
\end{tabular}

cryofocusing of the hydrocarbons in the samples. Two different separation systems were used in the GC. The first was a tandem capillary system including a megabore capillary column (SPB-1, Supelco) with a $5 \mu \mathrm{m}$ thick film of bonded non-polar dimethylsilicone stationary phase, in series with a second column (DB-5, J\&W Scientific) with a $1.5 \mu \mathrm{m}$ bonded film of methylphenylsilicone. This separation system could be used without removal of water from the ambient samples. The second separation system included an $\mathrm{Al}_{2} \mathrm{O}_{3}-\mathrm{KCl}$ PLOT column with a $5 \mu \mathrm{m}$ adsorbent layer Moisture removal was necessary with this system, achieved by passing the sample through a dry-ice water trap.

\section{Sampling sites}

Measurements were made at a number of sites in the Toronto area during the period from 1991-1993. In addition, four samples were taken in the Windsor tunnel on the border of Windsor, Ontario and Detroit, Michigan. Table 1 gives details for each site including the number of samples collected and used for the CMB modelling. There were four roadside sites, two downtown sites, aircraft samples over Toronto and the master urban site at York University. The downtown sites are expected to be affected by roadway emissions, although samples were not taken at the roadside itself. The York University site is expected to be affected by all types of emissions in the city. There are highways, airports, residential areas and gasoline storage facilities in the vicinity of the University. Samples were collected both in summer and winter at York University. Samples were randomly acquired during daylight hours at all sites. The sampling program, while random, was designed to avoid samples taken in the early morning when a nighttime inversion may be present. At York University, approximately half the samples were taken in the mid morning and half in the afternoon. During the SONTOS 92 study, aircraft samples were taken at numerous locations along a flight line between BinbrookToronto-Hastings. Only samples taken over the city of Toronto, at an altitude of $600-800 \mathrm{~m}$, have been included here.

\section{Source-receptor modelling}

The CMB7 model (Watson et al., 1990) was used in this study. The model requires estimates of source profiles and measured receptor profiles. The mass balance equation is solved by an effective variance weighted least squares estimation method. Thus precision estimates for both source profiles and receptor profiles are required. Fitting species, used in the calculation of source contribution estimates, and nonfitting (floating) species can both be included in the profiles. A consistent set of fitting species was used in all calculations 


\section{R. MCLAREN et al.}

as shown in Table 2. The table indicates the mass fraction that each fitting species contributes to total NMHC for that particular profile. The mass not accounted for in the profiles of Table 2 can generally be accounted for by all other non-fitting NMHCs for that profile, $\mathrm{C} 2-\mathrm{C} 12$ in general. The 12 species in Table 2 were chosen based upon availability in source and receptor data at all sites, relatively long lifetime in the troposphere as indicated by their rate of reaction with the hydroxyl radical, and anticipated dominance of their ambient concentrations from the sources included. A speciated emissions inventory was not available for this region to verify that ambient concentrations of each fitting species are expected to be dominated by the sources included in the CMB modelling. Despite this, the species chosen are expected to have significant contributions from the gasoline based sources, greater than $60 \%$ and much higher for most species. This expectation is based upon knowledge of the contribution of these sources to the same species in other urban areas (Harley et al., 1992) and knowledge that these species are significant components in gasoline in Ontario. The fastest reacting species included was ethylene, while the slowest was acetylene with rates of reaction with the hydroxyl radical of $8.7 \times 10^{-12} \mathrm{~cm}^{3}$ molecules ${ }^{-1} \mathrm{~s}^{-1}$ and $7.7 \times 10^{-13} \mathrm{~cm}^{3}$ molecules ${ }^{-1} \mathrm{~s}^{-1}$, respectively at room temperature (Atkinson, 1986). This corresponds to a range of lifetimes from about $16-180 \mathrm{~h}\left([\mathrm{OH}]=2.0 \times 10^{6}\right.$ molecules $\mathrm{cm}^{-3}$ ).

Five source profiles were used to represent emissions from gasoline vehicles: exhaust, winter gasoline, summer gasoline, winter gasoline vapour and summer gasoline vapour (Table 2). At roadside sites, these profiles would be expected to fully represent emissions from gasoline vehicles in operation, including exhaust, running loss and some fraction of resting loss emissions. At non-roadside sites, we expect these profiles to represent emissions from operational vehicles as well as evaporative emissions from stationary vehicles, vehicle refuelling, gasoline distribution and storage facilities and gasoline spillage from any of the above sources.

The gasoline profiles were developed from speciated hydrocarbon data acquired from samples collected at service stations in Toronto during the summer of 1991 and winter of 1992 and analyzed by the Alberta Research Council (ARC, 1992). A total of 15 summer and 15 winter gasoline samples were collected and analyzed in that program. Weighted average profiles were calculated based upon sales by gasoline grade in Ontario. Standard deviations of the gasoline composition were calculated for each chemical species and for each gasoline grade separately. This measure gives some indication of the variability of the gasoline composition for each component. The average relative standard deviation for the 12 fitted species was $\pm 25 \%$. The vapour profiles were calculated from the average gasoline profile using all species. The calculation included the application of Antoine constants (Zwolinkski and Wilhoit, 1971; Boublik et al., 1984) to calculate the temperature dependent vapour pressure of each chemical species. Raoult's law was then applied to derive a final profile in mass units. Temperatures of $20^{\circ} \mathrm{C}$ and $0^{\circ} \mathrm{C}$ were used in the calculation of the summer and winter profiles, respectively. This approach has recently been reviewed and found to give accurate vapour compositions comparable to those generated by more sophisticated equation of state models (Radian, 1992). The relative standard deviation for each species in the vapour profiles was assumed to be the same as that found in the fuel composition due to the proportionality between vapour pressure and mole fraction of the species in the liquid fuel assumed in the calculation of vapour compositions.

The exhaust profile used in this modelling is derived from the work of Sigsby et al. (1987), and represents the average measurements made over a fleet of 46 older passenger vehicles operating on commercial gasoline. The profile was modified by the California Air Resources Board (CARB) who applied splitting factors for a few unresolved species (Gertler et al., 1993). Note that the exhaust profile is the only profile to include ethylene and acetylene, which thus act as tracers for motor vehicle exhaust. This exhaust profile was reported to give the best statistical performance measures when compared to other exhaust profiles in CMB modelling in recent tunnel studies (Wittorff et al., 1994). While this particular source profile did not include isoprene explicitly, measurements from several recent emissions testing programs indicate the presence of isoprene (2-methyl-1,3-butadiene) in exhaust from gasoline burning vehicles (Gabele, 1990; CARB, 1991; Coordinating Research Council, 1991). Isoprene is likely a combustion species due to its absence or negligible levels in gasoline. The data set from Phase 1 of the Auto/Oil AQIRP was used to calculate average isoprene emissions for the 10 vehicle "current" fleet and the 18 vehicle "older" fleet. The corresponding average levels of isoprene were found to be $0.158 \%$ and $0.201 \%$ of the NMHC exhaust mass, respectively. Data from a study on emissions from a methanol flexible fueled vehicle (FFV) by Gabele (1990) indicated levels of isoprene of $0.37 \%$ of the NMHC exhaust mass when the vehicle was operating on $100 \%$ gasoline. The NMHC fraction of isoprene in the exhaust was found to decrease as the percentage of methanol in the test fuel was

Table 2. Source profiles used in the chemical mass balance modelling

\begin{tabular}{lccccc}
\hline & \multicolumn{5}{c}{ Source profile NMHC fractions (by weight) } \\
\cline { 2 - 6 } Species & Exhaust & $\begin{array}{l}\text { Summer } \\
\text { gasoline }\end{array}$ & $\begin{array}{c}\text { Summer } \\
\text { vapour }\end{array}$ & $\begin{array}{c}\text { Winter } \\
\text { gasoline }\end{array}$ & $\begin{array}{c}\text { Winter } \\
\text { vapour }\end{array}$ \\
\cline { 2 - 6 } & $0.064 \pm 0.012$ & $0.028 \pm 0.012$ & $0.255 \pm 0.104$ & $0.082 \pm 0.024$ & $0.469 \pm 0.139$ \\
Is-Butane & $0.009 \pm 0.001$ & $0.007 \pm 0.003$ & $0.089 \pm 0.041$ & $0.016 \pm 0.011$ & $0.144 \pm 0.096$ \\
$n$-Pentane & $0.022 \pm 0.006$ & $0.049 \pm 0.015$ & $0.122 \pm 0.036$ & $0.048 \pm 0.016$ & $0.066 \pm 0.022$ \\
Isopentane & $0.049 \pm 0.015$ & $0.079 \pm 0.012$ & $0.264 \pm 0.041$ & $0.090 \pm 0.018$ & $0.173 \pm 0.035$ \\
$n$-Hexane & $0.009 \pm 0.001$ & $0.026 \pm 0.005$ & $0.019 \pm 0.004$ & $0.026 \pm 0.005$ & $0.009 \pm 0.002$ \\
$n$-Heptane & $0.009 \pm 0.002$ & $0.012 \pm 0.003$ & $0.0024 \pm 0.006$ & $0.012 \pm 0.003$ & $0.0010 \pm 0.0003$ \\
2-Methylpentane & $0.019 \pm 0.001$ & $0.041 \pm 0.008$ & $0.041 \pm 0.008$ & $0.041 \pm 0.008$ & $0.020 \pm 0.003$ \\
3-Methylpentane & $0.014 \pm 0.001$ & $0.026 \pm 0.005$ & $0.023 \pm 0.005$ & $0.026 \pm 0.003$ & $0.011 \pm 0.001$ \\
Acetylene & $0.028 \pm 0.006$ & $0.000 \pm 0.0001$ & $0.000 \pm 0.0001$ & $0.000 \pm 0.0001$ & $0.000 \pm 0.0001$ \\
Ethene & $0.099 \pm 0.020$ & $0.000 \pm 0.0001$ & $0.000 \pm 0.0001$ & $0.000 \pm 0.0001$ & $0.000 \pm 0.0001$ \\
Benzene & $0.039 \pm 0.0018$ & $0.011 \pm 0.007$ & $0.005 \pm 0.003$ & $0.011 \pm 0.009$ & $0.0022 \pm 0.018$ \\
Ethylbenzene & $0.008 \pm 0.003$ & $0.017 \pm 0.004$ & $0.0007 \pm 0.0002$ & $0.012 \pm 0.003$ & $0.0002 \pm 0.0001$ \\
Isoprene & $0.0018 \pm 0.0004$ & $0.000 \pm 0.0001$ & $0.000 \pm 0.0001$ & $0.000 \pm 0.0001$ & $0.000 \pm 0.0001$ \\
\hline
\end{tabular}

A non-fitted species in the CMB modelling. 
increased $(0 \%, 25 \%, 50 \%, 85 \%$ and $100 \%$ methanol). There was no detectable isoprene in the exhaust when the vehicle operated on $100 \%$ methanol, indicating that isoprene is a combustion product specific to gasoline. Testing of six vehicles by the California Air Resources Board (CARB, 1991) indicates levels of isoprene in the exhaust ranging from $0 \%$ to $0.18 \%$ while the average was found to be lower, $0.06 \%$. The lower values found in the CARB testing most likely reflect the lower mileages on the vehicles tested and the more stringent emissions control technology. All three studies above show higher isoprene fractions of total NMHC in the cold start emissions (BAG1) than the weighted average composite values. This may be indicative of the relative efficiency of the catalytic convertor in removing isoprene from the exhaust gases. For this reason, newer vehicles whose catalytic convertors have not degraded can be expected to have lower fractions of isoprene in the exhaust gases. This observation is supported by the Auto Oil Study results where the "current" fleet, with newer vehicles and lower mileages, showed smaller fractions of isoprene in their exhaust than the "older" fleet.

The profile shown in Table 2 was extended to include $0.18 \%$ isoprene based upon the 28 vehicle average found in the current and older fleets of the AQIRP study. Isoprene was included as a floating species (non-fitted) in the modelling. This implies that the value included for isoprene in the source profiles did not influence the calculation of a source estimate, but the model still calculates an isoprene concentration at the receptor site attributable to the exhaust source contribution.

Average receptor profiles for input to the CMB model were calculated for each urban site using all samples. Normalized receptor profiles (relative to isopentane) were visually compared to those observed at the master site at York University. The profiles were very comparable indicating that similar sources were contributing to the ambient hydrocarbons measured at the sites. Exceptions were higher than normal levels of propane at the Bay Street site, and higher than normal levels of olefins in the Windsor Tunnel. To estimate the sample variability in profiles observed at sites with a small number of samples, mass fractions of observed NMHC were calculated for all species for each sample. Relative standard deviations in the mass fractions were calculated for each species at each site and the average relative standard deviations (for the 12 CMB fitting species) were then calculated. The average relative standard deviation in the mass fraction was assumed to give some measure of the variability of sources that were contributing at each site. The average relative standard deviations ranged from $12 \%$ at the Windsor Tunnel to $32 \%$ at the Hwy 400 site. The low value of this measure at the Windsor site may indicate a smaller variability in sources contributing to the measured hydrocarbons compared to other sites. This gives more confidence in the representativeness of the samples that were taken at the Windsor Tunnel site, despite the low number.

The CMB model requires that the uncertainty in the concentration of each species in the receptor profile be input to the model. The uncertainty for each species in the profiles was calculated assuming two contributions to the uncertainty; $\pm 20 \%$ measurement precision for each species and an overall potential error of $\pm 10 \%$. The uncertainty due to measurement precision was reduced by the square root of the number of samples represented in the profile. Purposefully, these uncertainty measures do not reflect the variability seen in observed concentrations of individual species that can be very high due to varying meteorological conditions or varying temporal behaviour of source emissions. For York University, the data were further sectored by season and by wind direction to allow CMB modelling on spatial and temporally resolved averages.

\section{RESULTS AND DISCUSSION}

\section{Hydrocarbon distributions}

One of the most abundant hydrocarbon species in the urban atmosphere is isopentane. Isopentane is a major component of gasoline, is present in exhaust, and makes up a significant fraction of gasoline vapour due to its high volatility. The correlation between isopentane and $n$-pentane measured at York University is shown in Fig. 2. The correlation coefficient, $r=0.99$, is one of the best between pairs of species and can be expected due to their presence in similar

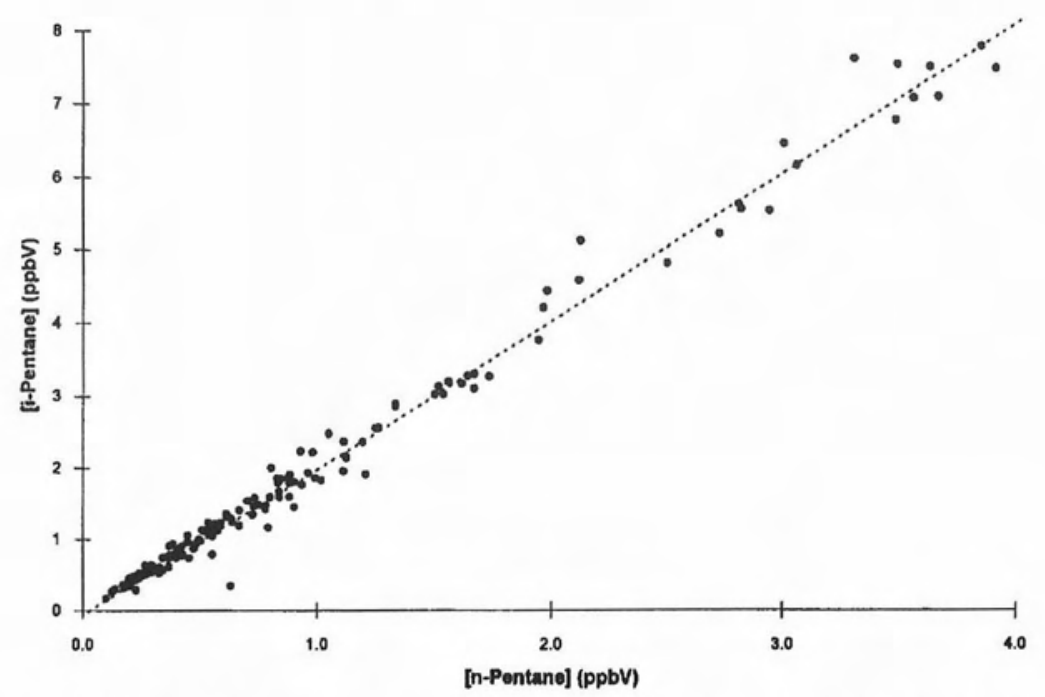

Fig. 2. Linear correlation between isopentane and $n$-pentane for observations made at York University during the summer of 1992. Slope $=2.03 \pm 0.02$, Y-intercept $=-0.02 \pm 0.02, r=0.99$. 


\section{R. McLAREN et al.}

sources and their similar volatility. Paired correlations are one way to identify possible anthropogenic sources of hydrocarbon species.

The median hydrocarbon distribution measured at York University is presented in Fig. 3a along with distributions obtained from other international urban areas. The list of species includes $\mathrm{C} 2-\mathrm{C} 7$ paraffins, olefins and aromatics that are found in relatively high levels in the urban atmosphere. To facilitate comparison of distributions that may be on widely varying absolute mixing ratio scales, the distributions have been normalized to isopentane. The distribution measured at York University is very similar to the 39-city U.S. average distribution reported by Jeffries et al. (1989). This would indicate that the source mixtures are similar in urban centres in the two countries. The York distribution is less similar to the distributions seen in Sydney, Australia or London, England (Blake et al., 1993). The latter two profiles appear enriched in acetylene and olefins, species known to be reactive on vehicle catalytic convertors. This may indicate a difference in mobile source emissions control technology in North America compared to Australia or London. Indeed, it is known that three-way catalysts, now mandatory in North America, are less common in London.

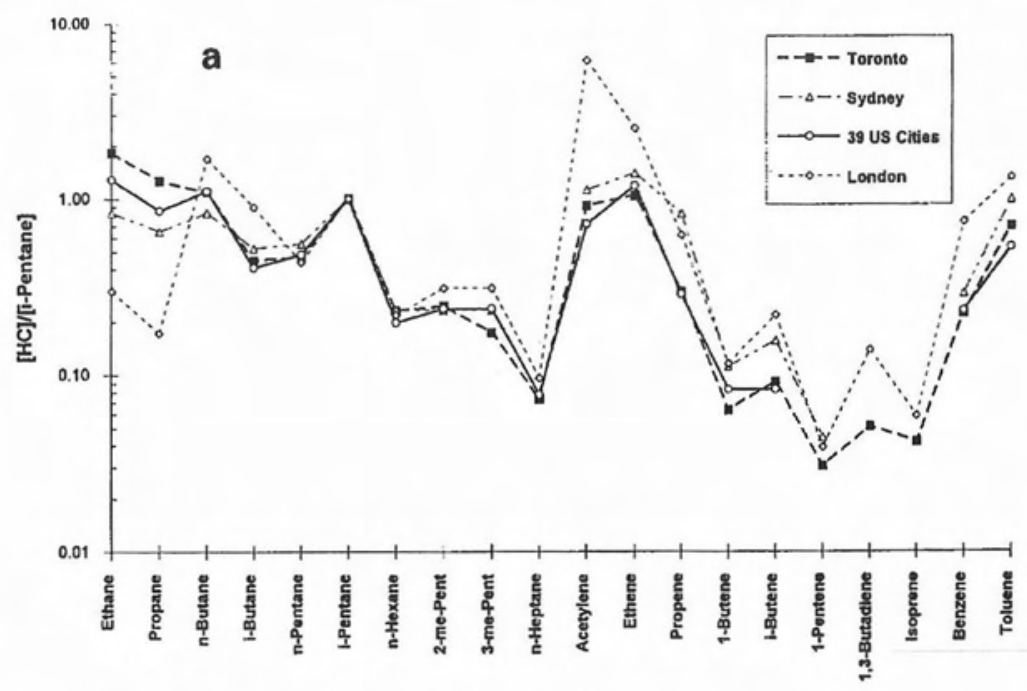

Fig. 3a. Comparison of urban hydrocarbon distributions at several cities with those measured at York University.(Toronto).

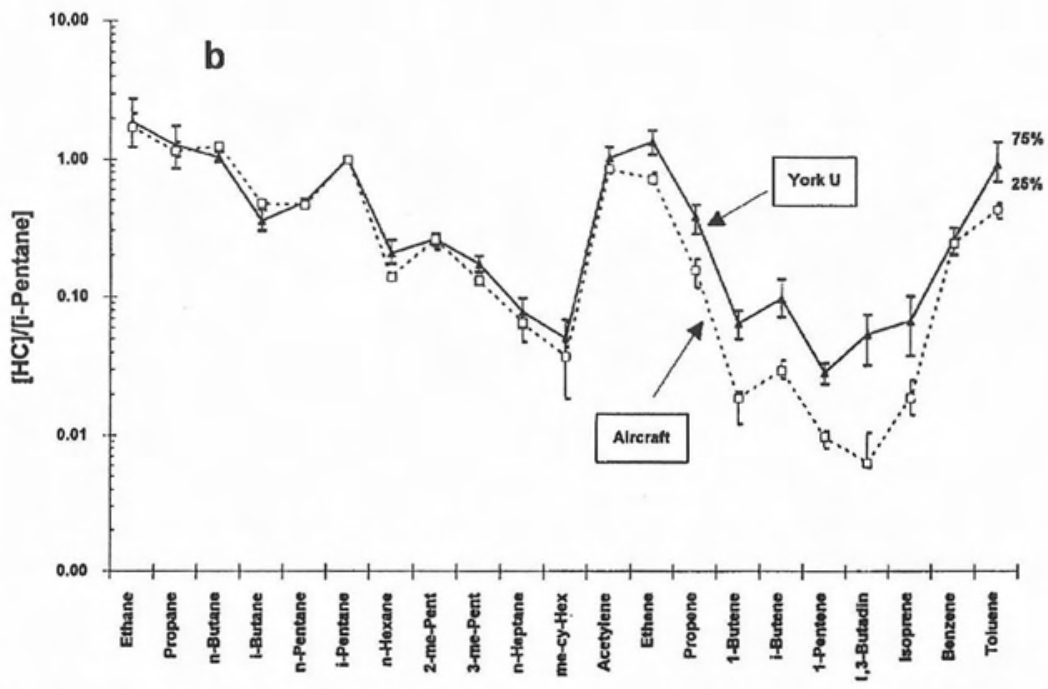

Fig. 3b. Comparison of hydrocarbon distributions recorded at York University (ground level) and by aircraft measurements above Toronto during SONTOS. 
The observed hydrocarbon distributions at York University are fairly constant from one year to another. The only significant difference between the 1991 and 1992 summer distributions was a reduction in the relative concentrations of isoprene and 1-pentene in 1992. The significance of the reduction in 1-pentene is not known whereas the reduction in isoprene can be attributed to the cooler than average summer that year. Cooler temperatures with increased cloud cover would result in a decrease in isoprene emissions from vegetation. Only minor differences were seen between the winter and summer distributions at York University, apart from the decrease in isoprene in winter.

A comparison of median hydrocarbon distributions at ground level (York University site) and aloft (SONTOS aircraft samples) in Toronto is given in Fig. 3b. The error bars represent the 25 th and 75 th percentiles of the relative concentrations for each species. The distributions are remarkably similar for acetylene, benzene and paraffins. The compounds have relatively slow rates of reaction with the hydroxyl radical and have a negligible rate of reaction with $\mathrm{O}_{3}$. In contrast, the alkenes are appreciably depleted relative to isopentane aloft of Toronto compared to the ground level observations. This general observation has been made previously in other urban areas by Jeffries et al. (1989). It is evident that the degree of depletion is greater for the faster reacting alkenes such as 1,3-butadiene and isoprene, compared to the slowly reacting alkenes, such as ethene and propene. The relative depletion of fast reacting species in the upper air is consistent with the characteristics of a transported air parcel that has more time for chemical depletion relative to the fresh emissions at ground level.

Source apportionment by chemical mass balance modelling

Table 3 summarizes the CMB modelling results for each site. Source estimates of NMHCs are given for exhaust, gasoline and gasoline vapour along with uncertainties at each site. It is important to note that the source estimate allocated by the CMB model includes all NMHC species, fitting and non-fitting. The 1991-1993 ambient data at York University were sectored into summer (June-August) and winter (December-February) seasons. Separate modelling runs were made for the two seasons as shown in the table. The appropriate gasoline and gasoline vapour sources were used in the model depending on the season of sampling (Table 2). The CMB model runs all had $R^{2}$ values (the fraction of measured concentration variance attributable to variance in the calculated concentrations) greater than 0.9 , indicating a good fit between observed and calculated concentrations. The Chi square values (the sum of squares of differences between the calculated and measured fitting species concentrations) were all less than 4.0 , a suggested maximum value above which, species concentrations would not adequately be explained by the source mixture (Watson et al., 1990). The model indicated a collinearity problem on two of the runs (Highway 401 and Windsor Tunnel). Collinearity can result from source profiles that are not sufficiently distinguishable, from high uncertainties in the source or receptor profiles, or from some combination of the above. To test the calculated gasoline and vapour source contributions for the two sites showing collinearity, additional CMB runs were performed assuming only two sources, exhaust and gasoline vapour. In these cases, the mass apportioned to the vapour source remained small, equivalent to the old estimate within error. The mass apportioned to the exhaust source increased, approximately given by the sum of the old estimate of gasoline + exhaust. These results showed that there was similarity between the exhaust and gasoline sources. This result is not too surprising since it is known that there is significant unburned gasoline in tailpipe exhaust. In addition, for combustion events that occur during severe enrichments (such as during hard accelerations or decelerations), one expects further enrichment of the exhaust with unburned gasoline, above what might be measured with the comparatively gentle driving cycle used in the FTP.

The relative source contributions are presented on a percentage scale for each receptor site in Fig. 4. In

Table 3. CMB estimates of source contributions at each site

\begin{tabular}{lccccccc}
\hline & \multicolumn{3}{c}{ Estimated source contribution } & & \multicolumn{3}{c}{ Isoprene } \\
\cline { 2 - 3 } $\begin{array}{l}\text { Sampling } \\
\text { site }\end{array}$ & $\begin{array}{c}\text { Exhaust } \\
\left(\mu \mathrm{g} \mathrm{m}^{-3}\right)\end{array}$ & $\begin{array}{c}\text { Gasoline } \\
\left(\mu \mathrm{g} \mathrm{m}^{-3}\right)\end{array}$ & $\begin{array}{c}\text { Vapour } \\
\left(\mu \mathrm{g} \mathrm{m}^{-3}\right)\end{array}$ & & $\begin{array}{c}\text { Calculated } \\
\left(\mu \mathrm{g} \mathrm{m}^{-3}\right)\end{array}$ & $\begin{array}{c}\text { Measured } \\
\left(\mu \mathrm{g} \mathrm{m}^{-3}\right)\end{array}$ & $\begin{array}{c}\text { Ratio } \\
\text { Meas./Calc. }\end{array}$ \\
\hline Bay Street & $100 \pm 13$ & $22.0 \pm 8.8$ & $23.9 \pm 5.8$ & & $0.183 \pm 0.040$ & $0.337 \pm 0.019$ & $1.84 \pm 0.42$ \\
Wind. Tun. & $878 \pm 132$ & $268 \pm 82$ & $57 \pm 34$ & & $1.61 \pm 0.35$ & $0.375 \pm 0.038$ & $0.23 \pm 0.06$ \\
Hwy 400 & $175 \pm 23$ & $50.8 \pm 14.9$ & $22.4 \pm 7.8$ & & $0.320 \pm 0.070$ & $0.227 \pm 0.017$ & $0.71 \pm 0.16$ \\
Hwy 401 & $122 \pm 17$ & $19.0 \pm 8.9$ & $6.0 \pm 3.3$ & & $0.221 \pm 0.049$ & $0.141 \pm 0.011$ & $0.64 \pm 0.15$ \\
CN Tower & $81.2 \pm 10.9$ & $36.3 \pm 7.2$ & $6.3 \pm 3.1$ & & $0.150 \pm 0.033$ & $0.517 \pm 0.034$ & $3.44 \pm 0.78$ \\
Queens Pk. & $94.6 \pm 13.4$ & $45.1 \pm 9.8$ & $17.0 \pm 5.2$ & & $0.176 \pm 0.038$ & $0.792 \pm 0.060$ & $4.51 \pm 1.03$ \\
YU-summer & $34.9 \pm 5.2$ & $25.1 \pm 4.8$ & $7.2 \pm 2.4$ & & $0.066 \pm 0.014$ & $0.319 \pm 0.032$ & \\
YU-winter & $66.1 \pm 10.3$ & $18.5 \pm 6.8$ & $16.7 \pm 5.0$ & & $0.121 \pm 0.012$ & $0.113 \pm 0.012$ & $0.93 \pm 0.23$ \\
\hline
\end{tabular}


this way, the contributions of the different sources to gasoline based NMHC can be compared. These percentages do not reflect the contribution of these sources to total NMHCs in the atmosphere. Other sources can contribute significantly to the total ambient organic load, but for species that have not been used as fitting species here. The emphasis here is on a relative comparison of gasoline based emission sources, which are dominated by on-road mobile sources.

The highest NMHC concentrations were seen in the Windsor tunnel, followed by the roadside sites, the downtown sites, York University in winter and York University in summer last. Thus, the level of ambient NMHCs decreases with sampling distance from the roadside. Because of the high NMHC levels, tunnel and roadside samples are expected to be more completely dominated by the sources used in this receptor modelling study, and specifically from on-road vehicle emission modes such as exhaust and running loss emissions. With increasing distance from the roadside, other gasoline based sources, such as gasoline spillage, diurnal emissions, hot soak emissions, refuelling emissions and gasoline distribution and storage emissions will impact on the receptor site. The observation of higher ambient levels of NMHCs at York University in the winter is typical for many urban areas and can be accounted for by a number of factors, including slower photochemical degradation of HCs and shallower mixed layers in the winter.

As seen in Fig. 4, the most dominant gasoline based source at all the sites is vehicle exhaust. Its contribution to total gasoline based NMHCs ranges from $52 \%$ to $83 \%$. The highest percentages are seen at the roadside sites $(69-83 \%)$, followed by the downtown sites $(60-66 \%)$, followed by the York University site ( $52 \%$ summer, $65 \%$ winter). Unburned gasoline contributes between $13 \%$ and $37 \%$ of total gasoline based NMHCs. The highest gasoline percentages are seen at York University in the summer (37\%), followed by the downtown sites (both $29 \%$ ), followed by the roadside sites and York University in the winter

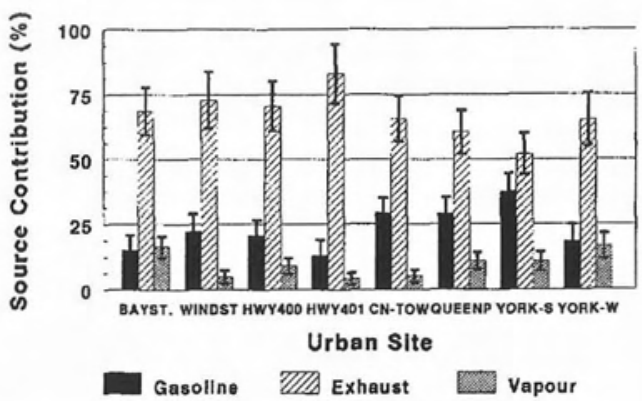

Fig. 4. Contributions of sources to gasoline based NMHCs calculated by the chemical mass balance model at urban sites in Toronto. Bay St., Windsor Tunnel, Hwy 400 and Hwy 401 are roadside sites, $\mathrm{CN}$-Tower and Queens Park are nonroadside downtown sites. Calculations were made for the York University site by sectoring observations to summer (S) and winter (W) seasons.
$(13-22 \%)$. The trend becomes clear from the above discussion; there is a decrease in the relative contribution of exhaust to total gasoline based NMHCs as one moves away from the roadside, coincident with an increase in the contribution of unburned gasoline. The above observation holds true except for the York University wintertime samples which show similar unburned gasoline contributions as those seen at the roadside sites. There is a significant difference in the contribution of unburned gasoline at York University in winter compared to summer.

CMB modelling was performed on the wind resolved summer data at York University to determine if unburned gasoline could be associated with a particular wind sector. The results are given in Fig. 5.
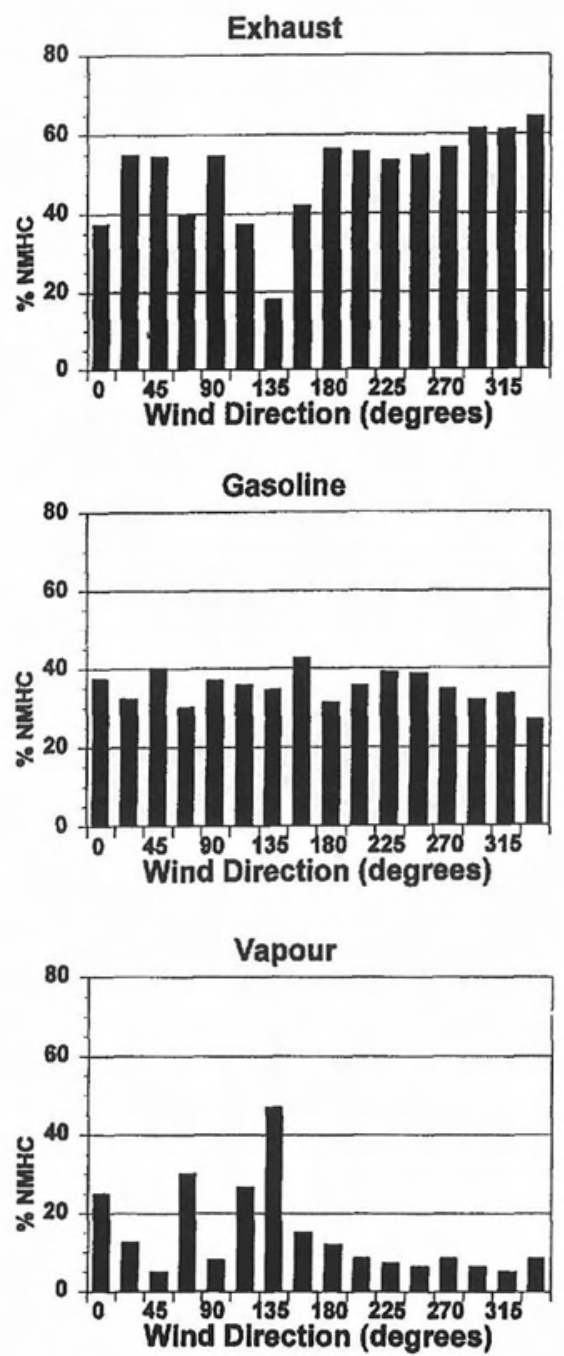

Fig. 5. Relative contributions of sources to gasoline based NMHCs at York University (summer 1991-92) calculated by the chemical mass balance model. Results were calculated for data sets sectored by wind source direction where $0^{\circ}$ is north, $90^{\circ}$ is east. 
Percentage contributions to gasoline based NMHCs are indicated as a function of wind source direction with $0^{\circ}$ representing north. No obvious or significant source of unburned gasoline was identified. The percentage contribution of unburned gasoline to gasoline based NMHCs is about $30-40 \%$ in all sectors. Significant sources of gasoline vapour are apparent in the ESE and SE sectors. Not coincidentally, this is the direction of two tank farms located within a few kilometres of York University. Significant gasoline vapour emissions are expected from this type of source.

The relative contribution of gasoline vapour to gasoline based NMHCs is relatively small on average at all sites, ranging from $4 \%$ to $17 \%$ for the CMB results derived from the average hydrocarbon distributions (Fig. 4). Sources that may contribute to the appearance of gasoline vapour in the urban area include evaporative emissions from motor vehicles, off road vehicles and other gasoline based equipment, refueling emissions at filling stations, emissions from the filling and storage of gasoline in underground storage tanks at filling stations and other evaporative emissions from the fuel marketing infrastructure.

The appearance of gasoline vapour at roadside sites, where hydrocarbon levels are higher, is expected to be indicative of evaporative emissions from motor vehicles that are in operation, including running loss emissions and resting loss emissions. A comparison was made between the relative amount of evaporative emissions (vapour) apportioned by the CMB model at these sites and those calculated using the latest Canadian mobile emissions factors model, MOBILE5C (Philpott, 1993), Table 4. Three MOBILE scenarios were run using different speeds, temperatures, Reid vapour pressures, and vehicle operating modes expected to be representative for the conditions found at the different sites. The details of the MOBILE5C model runs are given in Table 4 footnotes. The com- posite-vehicle-mix output of the model was used to simulate a mixture of light and heavy duty vehicles, although the prediction was very similar to that obtained by assuming passenger vehicles only, due to the dominance of passenger vehicles on the road.

Two CMB evaporative estimates and two MOBILE evaporative estimates are given in Table 4 which bracket a range of uncertainty. The two CMB evaporative estimates differ in their inclusion or exclusion of the unburned gasoline source estimate as a vehicle exhaust emission when calculating the mass percentage of evaporative emissions. In one case (footnote ${ }^{b}$ ), a modified exhaust source estimate was created by adding the exhaust source and unburned gasoline source estimates (see Table 3 ). This reflects an interpretation in which one assumes that the on-road unburned gasoline source allocated by the CMB model is actually unburned gasoline from the tailpipe itself. In the second estimate (footnote ${ }^{\circ}$ ), the assumption was made that the unburned gasoline comes from a non-exhaust source and was thus not considered when calculating the mass percentage of evaporative emissions. The two MOBILE evaporative estimates differ in their inclusion or exclusion of "resting loss" emissions as true on-road emissions. While running loss emissions are expected to be true on-road emissions, resting loss emissions can occur whether the vehicle is operating or not, and a significant fraction of these emissions may occur while the vehicle is at rest (U.S. EPA, 1991). The first estimate (footnote d) assumes that resting loss emissions occur away from the road and thus are not included when calculating the mass percentage of evaporative emissions. The second estimate (footnote ${ }^{\circ}$ ) assumes that all resting loss emissions occur when the vehicle is being operated and may thus overestimate actual on-road evaporative emissions. The different estimates outlined above provide some range of uncertainty associated with the definition of emissions in the MOBILE

Table 4. Comparison of relative mass of evaporativc emissions from MOBILE5C and CMB receptor results

\begin{tabular}{|c|c|c|c|c|c|}
\hline \multirow{2}{*}{$\begin{array}{l}\text { Sampling } \\
\text { site }\end{array}$} & \multirow[b]{2}{*}{ Model scenario ${ }^{a}$} & \multicolumn{2}{|c|}{$\begin{array}{l}\text { CMB evaporative source } \\
\text { NMHC estimate (mass \%) }\end{array}$} & \multicolumn{2}{|c|}{$\begin{array}{l}\text { MOBILESC evaporative source } \\
\text { NMHC estimate (mass \%) }\end{array}$} \\
\hline & & Estimate $1^{\mathrm{b}}$ & Estimate $2^{\mathrm{c}}$ & Estimate $1^{\mathrm{d}}$ & Estimate $2^{e}$ \\
\hline Bay Street & Summer, urban & $19.3 \pm 4.7$ & $16.3 \pm 4.0$ & 15.7 & 17.7 \\
\hline Hwy 400 & Summer, highway & $11.3 \pm 3.9$ & $9.0 \pm 3.1$ & 6.6 & 10.5 \\
\hline Hwy 401 & Winter, highway & $4.7 \pm 2.6$ & $4.1 \pm 2.2$ & 0.3 & 1.2 \\
\hline Wind. Tun. & Winter, highway & $6.1 \pm 3.6$ & $4.8 \pm 2.6$ & 0.6 & 2.5 \\
\hline
\end{tabular}

"Conditions used in mobile model scenarios are as follows. Summer: $T_{\min }=13.3^{\circ} \mathrm{C}, T_{\max }=25.6^{\circ} \mathrm{F}, \mathrm{RVP}=10.4 \mathrm{psi}$, 1 July 1992. Composite vehicle mixture. Vehicle registrations were those recommended for Ontario (Philpott, 1993). Winter: $T$ (fixed) $=4.5^{\circ} \mathrm{C}, \mathrm{RVP}=14.5 \mathrm{psi}, 1 \mathrm{January} 1992$. Composite vehicle mixture. Vehicle registrations were those recommended for Ontario (Philpott, 1993). Urban: $V=19.6 \mathrm{mph}$, FTP composite emissions mixture. Hwy: $V=65.0 \mathrm{mph}, 100 \%$ hot stabilized.

${ }^{\mathrm{b}} \mathrm{G}$ asoline source estimate was treated as a non-mobile source.

' Gasoline source estimate was included as exhaust.

${ }^{\mathrm{d}}$ Evaporative emissions include running loss. Other emissions are exhaust.

'Evaporative emissions include running loss and resting loss. Other emissions are exhaust.

${ }^{\prime}$ Mass apportioned to the vapour source in Table 3 is assumed to be an evaporative source. 


\section{R. MCLAREN et al.}

model and the interpretation of unburned gasoline in the ambient air at roadsides as originating from the tailpipe or not.

The relative mass of evaporative emissions predicted by the MOBILE5C model is in reasonable agreement with the CMB estimates at the two summer roadside sites. The same is not true at the two winter roadside sites. While all winter estimates show a reduction in the relative amount of vapour compared to summer, the MOBILE model appears to underpredict the relative amount of evaporative emissions compared to the CMB estimate, regardless of whether resting loss emissions were included as onroad emissions or not. A temperature of $4.5^{\circ} \mathrm{C}\left(40.1^{\circ} \mathrm{F}\right)$ was used in the MOBILE model for the winter simulation even though the temperatures for these sites was much lower. This was necessary since the mobile model will not calculate evaporative emissions for temperatures lower than $4.5^{\circ} \mathrm{C}\left(40^{\circ} \mathrm{F}\right)$. The evaporative emissions at low temperature are very uncertain, and the mobile models assume that they approach zero at temperatures of $40^{\circ} \mathrm{F}$ (U.S. EPA, 1993). The CMB results seem to indicate that evaporative emissions are not quite insignificant at these low temperatures ( $\sim 4 \%$ for the conditions at these sites), and could be more significant at $40^{\circ} \mathrm{F}$.

The question of the source of unburned gasoline still lingers. Some of the gasoline may be associated with excess emissions from the tailpipe as suggested by Harley et al. (1992). The present results indicate that this only partially accounts for the unburned gasoline since the unburned gasoline fraction increases as one moves away from the roadside. Excess gasoline spillage from multiple sources, also suggested by Harley et al. (1992), could account for this increase seen away from the roadside, but a seasonal dependence of this spillage is probably unlikely. Recall that the relative gasoline contribution to gasoline based NMHCs at York University in the wintertime is the same as that seen at the roadside (summer or winter) while the corresponding contribution of gasoline at York University in the summer is significantly higher. Another possible explanation is excess hot soak emissions. Hot soak emissions are those HC emissions coming from a vehicle during the period after the engine has been turned off. They can be attributed to fuel evaporation or leakage from the hot engine and fuel lines (U.S. EPA, 1991). A seasonal dependence in the magnitude of these emissions is probably reasonable for the following reasons. This type of emission is dependent on the temperature of the engine and fuel lines, which will be much lower in the winter than the summer. Also, the cool down of a hot component will be much faster in the winter than in the summer, based upon lower ambient temperatures. Furthermore, the cool down time for hot components under the hood could be extended significantly in the summer if the vehicle is exposed to solar radiation.

A number of CMB sensitivity runs were completed that are worth noting. Vapour profiles were cal- culated at temperatures ranging from $-10^{\circ} \mathrm{C}$ to $+30^{\circ} \mathrm{C}$. In general, an increase in temperature results in a decrease in the mass fraction of the more volatile species in the profile, namely the butanes and pentanes. The CMB modelling was repeated for a number of sites using these alternate profiles. In general, the new source estimates calculated by the CMB model with these new profiles were equivalent within error. Other sensitivity runs were completed to test the hypothesis that the differences in winter and summer gasoline compositions were responsible for the signifcant difference in the unburned gasoline contributions at York University in summer vs winter. In fact the reverse was observed. When the summer gasoline source profile was used for fitting of the winter ambient profile, the contribution of unburned gasoline decreased slightly. Conversely, when the winter gasoline source profile was used for fitting of the summer ambient profile, the contribution of unburned gasoline increased slightly. In both cases, the difference in the percentage contributions of raw gasoline compared to the base were less than the standard errors shown in Fig. 4. Thus, the sensitivity runs only served to increase the differences seen in summer and winter at York University.

\section{An anthropogenic source of isoprene}

The seasonal trend in isoprene levels at York University is presented in Fig. 6a. Levels of isoprene increase in the summer due to the well established emissions from biogenic sources, most notably from deciduous trees (Khalil and Rasmussen, 1992). These emissions are both temperature and light dependent, isoprene being a product of photosynthesis. The levels of isoprene seen in the city are lower than those at other rural sites such as Binbrook, Hastings and Dorset because of the lower density of foliage in the urban area. Still, reactivity weighted HC concentrations indicate that isoprene can be a significant contributor to ozone formation during hot summer conditions. Despite the predominance of snow cover in Toronto during the winter, which forces the dormancy of biogenic sources, isoprene levels still persist in the atmosphere. An analysis of winter data at York University shows a significant correlation between isoprene levels and 1,3-butadiene levels, Fig. 6b. Since 1,3-butadiene is a well known combustion product (Siegl et al., 1992), the good correlation between the two species is partial evidence that isoprene produced from gasoline combustion may be responsible for wintertime isoprene concentrations in the city.

The level of isoprene included in the exhaust profile is seen in Table 2, based upon data extracted from the AQIRP database (Burns et al., 1991) as discussed previously. Table 3 shows measured concentrations of isoprene and exhaust isoprene concentrations allocated by the CMB model (calculated isoprene). The ratio of these two quantities indicates whether the hypothesis, that isoprene concentrations in the atmosphere can be accounted for by exhaust based iso- 
Analysis of motor vehicle sources

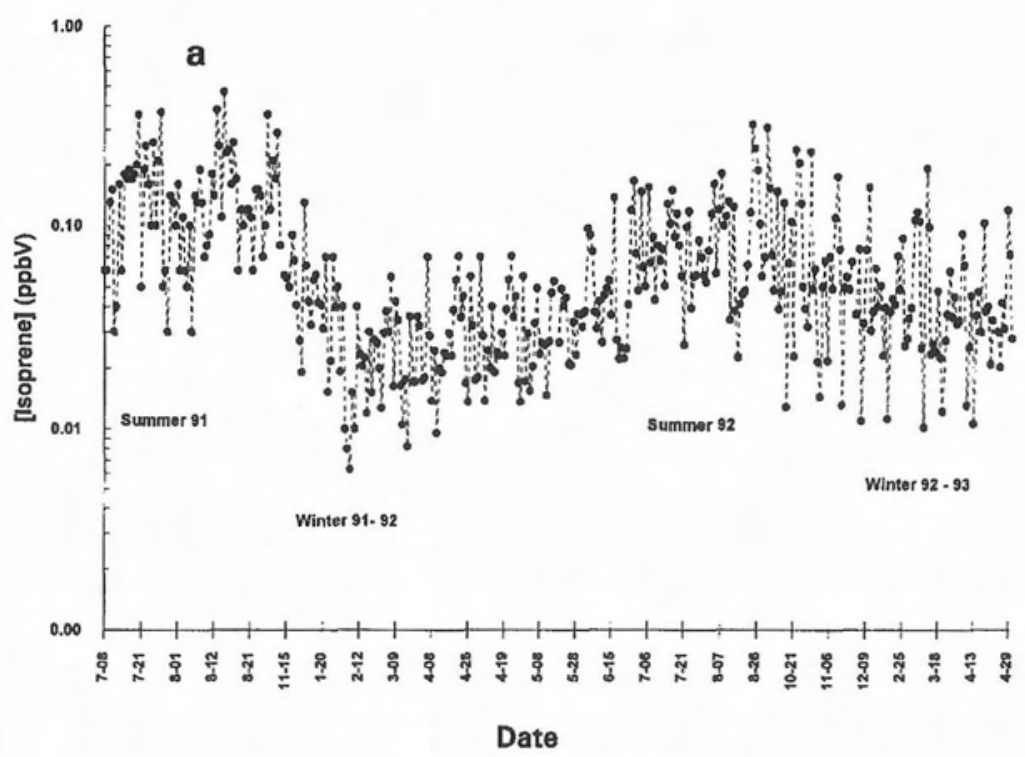

Fig. 6a. Seasonal distribution of isoprene mixing ratios at York University.

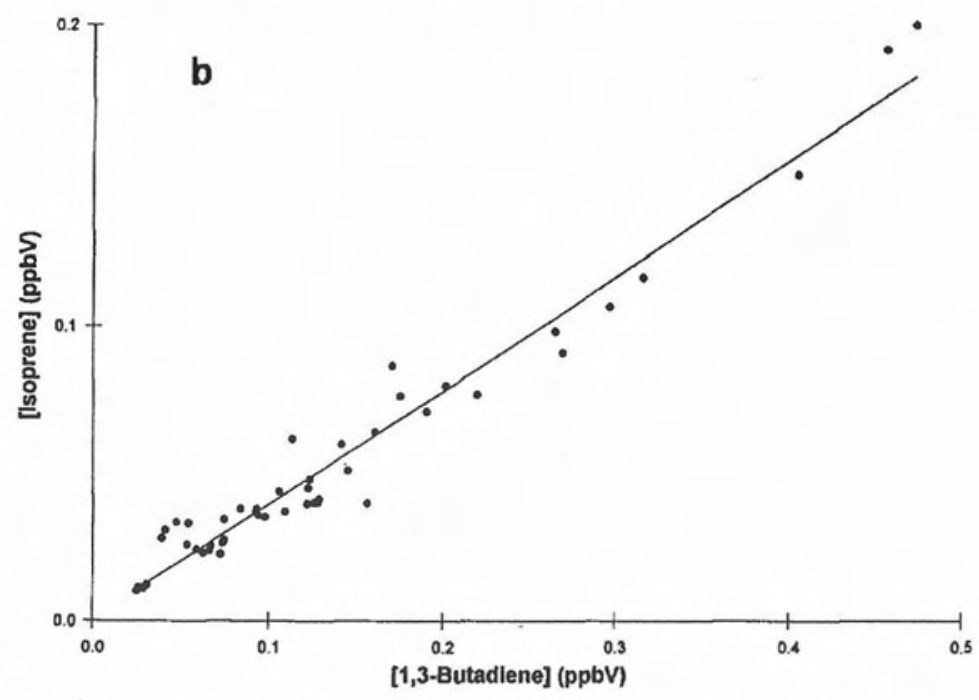

Fig. 6b. Linear correlation between isoprene and 1,3-butadiene for observations at York University during the winter of 1992. Slope $=0.38 \pm 0.02$, Y-intercept $=0.001 \pm 0.002, r=0.98$.

prene, is supported by the data. A ratio of 1.0 supports the hypothesis while a ratio greater than 1.0 indicates that there are other significant sources of isoprene in the atmosphere (such as biogenic emissions). The roadside sites, apart from the Windsor Tunnel, have measured/calculated ratios that are close to 1.0 within two standard deviations. The Windsor Tunnel had lower than expected isoprene levels. In the summer, the two downtown sites and York University have ratios significantly greater than 1.0 . This is expected since these sites are more removed from the roadside, and biogenic emissions are likely contributing to the observed concentrations. A significant amount of greenery exists at the Queens Park and York University sites. York University is not expected to be influenced by isoprene emissions in the winter. For the winter average ambient data at that site, the measured/calculated isoprene ratio is $0.93 \pm 0.23$. This is strong evidence that isoprene levels in exhaust, as measured during the AQIRP, can account for the observed isoprene in the urban atmosphere during winter.

The measured/calculated isoprene ratio from the wind resolved receptor modelling at York University 
is shown in Fig. 7. The lines bracketing the symbols indicate the standard error range for each season. It is seen that the measured/calculated isoprene ratio is close to 1.0 during the wintertime in all sectors. The summer data show ratios significantly greater than 1.0. The highest ratio is seen when wind is from the $\mathrm{NNW}$, indicating that biogenic emissions from this sector may be high. Not coincidentally, this sector also shows the lowest overall NMHC levels, indicating minimum anthropogenic emissions. The SW and SSW sectors have lower than average isoprene ratios in the summer, indicating possible lower biogenic emissions. Not surprisingly, the SW sector contains Toronto International Airport at a distance of about $14 \mathrm{~km}$, while the SSW sector contains a $5 \mathrm{~km}$ section of Highway 401, one of Canada's busiest highways, that is in a direct line towards York University at a distance of about $8 \mathrm{~km}$. An isoprene ratio approaching 1.0 in these regions supports the observation of minimum biogenic land use and significant mobile source activity.

The above observations give a strong indication that gasoline combustion can lead to observable levels of isoprene in an urban area such as Toronto, and can account for a significant fraction (if not all) of the atmospheric levels of this species in winter. During summer however, the contribution of mobile source related isoprene to the total observed levels at nonroadside sites is much less. The calculated isoprene levels at each non-roadside summer site (Table 3) account for approximately $20-30 \%$ of the observed isoprene. This represents a maximum limit to the estimated mobile source contribution since photochemical oxidation of isoprene would decrease the observed levels, dependent on the source to receptor distance and meteorological conditions. This percent-

measured/calculated isoprene

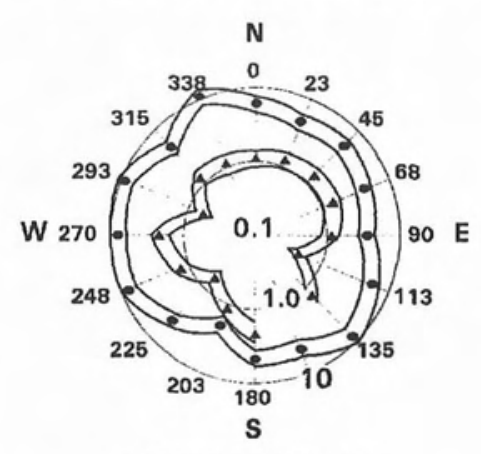

- Summer $\triangle$ Winter

Fig. 7. Measured/calculated isoprene concentrations. Isoprene concentrations were calculated by the CMB model based upon the assumed $0.0018 \%$ NMHC mass assumed in the exhaust profile. The radial component represents the ratio which is presented on a log scale ( 0.1 centre to 10.0 outer ring). age could also be much lower during warmer than average conditions because of the extreme temperature dependence of isoprene emissions from biogenic sources. Hot summer conditions are generally conducive to enhanced ozone formation. The existence of an anthropogenic source of isoprene should be considered though when VOC sampling is situated close to a roadside. Furthermore, because of variable temporal traffic patterns, one may expect that isoprene emitted from vehicle exhaust will lead to variable temporal patterns of isoprene in the atmosphere in urban areas. A morning rush hour isoprene peak in the urban area may be indicative of an exhaust related isoprene emission for example.

\section{CONCLUSIONS}

Relative hydrocarbon distributions measured in ambient air at York University and aloft of Toronto during the Southern Ontario Oxidants Study of 1992 have been presented. The distribution at ground level is most similar to the 39-city U.S. average. Differences have been noted between the Toronto profile and those measured in Sydney and London. The aloft distribution is depleted in alkenes compared to the ground level distribution.

Chemical mass balance modelling was used to apportion the observed distributions of gasoline based hydrocarbon species at York University, roadside sites, and downtown sites in Toronto to gasoline based sources. The most dominant contributing source was vehicle exhaust. The relative amount of unburned gasoline at York University was found to be significantly higher in the summer than the winter, and significantly higher than that observed at roadside sites. This observation would be consistent with excess unburned gasoline emitted from vehicles after termination of operation (hot soak emissions). The amount of gasoline vapour apportioned by the CMB model using measured NMHC distributions at roadside sites was consistent with the relative amount of on-road evaporative emissions calculated with the MOBILE model for warm summer conditions. During winter conditions however, the MOBILE model underpredicted the relative amount of gasoline vapour at roadside sites. It appears that at low temperatures, the MOBILE model assumes zero or very low running loss emissions, contrary to what has been observed here.

The possibility of an anthropogenic source of isoprene in the urban area has been proposed and tested. The inclusion of an isoprene flux in the exhaust source profile, consistent with that measured in the Auto/Oil Air Quality Improvement Research Program, resulted in calculated isoprene concentrations that are in general agreement with those observed at roadside sites and at York University in the winter. Smaller than expected isoprene concentrations were seen in the Windsor Tunnel. The levels of isoprene observed 
at York University in the winter can be completely accounted for by the exhaust source.

Acknowledgements--The authors from the National Research Council would like to thank the Panel on Energy Research and Development and Transport Canada for financial support. The authors from York University would like to thank the Ontario Ministry of the Environment and Energy, the Atmospheric Environment Service (AES) and the National Science and Engineering Research Council (NSERC) for financial support. H. Niki is the holder of the British Gas/Consumers Gas/NSERC/AES Industrial Research Chair in Atmospheric Chemistry.

\section{REFERENCES}

Alberta Research Council (1992) Composition of Canadian Summer and Winter Gasolines: 1991-1992. The Canadian Petroleum Products Institute, Ottawa, Canada.

Aronian P. F., Scheff P. A. and Wadden R. A. (1989) Wintertime source-reconciliation of ambient organics. Atmospheric Environment 23, 911-920.

Atkinson R. (1986) Kinetics and mechanisms of the gasphase reactions of the hydroxyl radical with organic compounds under atmospheric conditions. Chem. Rev. 86, 69-201.

Blake N. J., Penkett S. A., Clemitshaw K. C., Anwyl P., Lightman P. and Marsh A. R. W. (1993) Estimates of atmospheric hydroxyl radical concentrations from the observed decay of many reactive hydrocarbons in welldefined urban plumes. J. geophys. Res. 98, 2851-2864.

Boublik T., Fried V. and Hala E. (1984) The Vapour Pressures of Pure Substances, 2nd Edn. Elsevier, Amsterdam.

Burns V. R., Benson J. D. and Hochhauser A. M. (1991) Description of the Auto/Oil Air Quality Improvement Research Program. Soc. Auto. Engng, Paper \# 912320, $1-28$.

California Air Resources Board (1991) Proposed Reactivity Adjustment Factors for Transitional Low-Emission Vehicles-Technical Support Document. Mobile Source Division, CARB, Sacramento, California.

Calvert J. G., Heywood J. B., Sawyer R. F. and Seinfeld J. H. (1993) Achieving acceptable air quality: Some reflections on controlling vehicle emissions. Science 261, 37-45.

Canadian Council of Ministers of the Environment (1990) Management Plan for Nitrogen Oxides and Volatile Organic Compounds-Phase I. CCME-EPC/TARE-E, Ottawa, Ontario, Canada.

Carter W. P. L. and Atkinson R. (1989) Computer modeling study of incremental hydrocarbon reactivity. Envir. Sci. Technol. 23, 864-880.

Cass G. R. and McRae G. J. (1983) Source-receptor reconciliation of routine air monitoring data for trace metals: An emission inventory assisted approach. Envir. Sci. Technol. 17, 129-138.

Chameides W. L., Fehsenfeld F., Rodgers M. O., Cardelino C., Martinez J., Parrish D., Lonneman W., Lawson D. R., Rasmussen R. A., Zimmerman P., Greenberg J., Middleton P. and Wang $\Upsilon$. (1992) Ozone precursor relationships in the ambient atmosphere. J. geophys. Res. 97, 6037-6055.

Coordinating Research Council (1991) The Auto/Oil Air Quality Improvement Research Program Phase I data set is available from the Coordinating Research Council, 219 Perimeter Center Parkway, Atlanta, Georgia. The data set is described in the following publication: Pollack A. K. Cohen J. P., Noda A. M. (1991) Auto/Oil Air Quality Improvement Research Program: Description of Phase I Working Data Set. SYSAPP-91/100, Systems Applications International, San Rafael, California.
Dann T. and Wang D. (1992) Volatile organic compound measurements in Canadian urban and rural areas: 1989-1990. Air and Waste Management Association, 9275.16, 1-16, 85th Ann. Meeting and Exhibition, Kansas City, Missouri.

Fujita E. M., Croes B. E., Bennet C. L., Lawson D. R., Lurmann F. W. and Main H. H. (1992) Comparison of emission of ambient concentration ratios of $\mathrm{CO}, \mathrm{NO}$ and NMOG in California's South Coast Air Basin. J. Air Waste Man. Ass. 42, 264-276.

Gabele P. A. (1990) Characterization of emissions from a variable gasoline/methanol fueled vehicle. J. Air Waste Man. Assoc. 40, 296-304. Detailed hydrocarbon composition was available upon request from the author, P. A Gabele, U.S. Environmental Protection Agency, Research Triangle Park, North Carolina.

Gertler A. W., Fujita E. M., Pierson W. R. and WittorffD. N. (1993) Apportionment of VOC Tailpipe vs Non-Tailpipe Emissions in the Fort McHenry and Tuscarora Tunnels. Regional Photochemical Measurement and Modelling Studies Specialty Conf., Air and Waste Management Association, San Diego, California, 8-12 November.

Harley R., Hannigan M. P. and Cass G. R. (1992) Respeciation of organic gas emissions and the detection of excess unburned gasoline in the atmosphere. Envir. Sci. Technol. 26, 2395-2408.

Harley R., Russell A. G., McRae G. J., Cass G. R. and Seinfeld J. H. (1993) Photochemical modelling of the Southern California Air Quality Study. Envir. Sci. Technol. 27, 378-388.

Ingalls M. N. (1989) On-road vehicle emission factors from measurements in a Los Angeles Area Tunnel. 89-137.3, Air and Waste Management Association, 86th Ann. Meeting and Exhibition, Denver, Colorado.

Jeffries H. E., Sexton K. G., Arnold J. R. and Kale T. L. (1989) Validation Testing of New Mechanisms with Outdoor Chamber Data. Vol. 2: Analysis of VOC Data for the CB4 and CAL Photochemical Mechanisms. EPA-600/389-010b. U.S. Environmental Protection Agency, Research Triangle Park, North Carolina.

Kenski D. M., Wadden R. A., Scheff P. A. and Lonneman W. A. (1993) A receptor modelling approach to VOC emission inventory validation in five U.S. Cities. 93-WP. 100.04, Air and Waste Management Association, 86th Ann. Meeting and Exhibition, Denver, Colorado.

Khalil M. A. K. and Rasmussen R. A. (1992) Forest hydrocarbon emissions: Relationships between fluxes and ambient concentrations. J. Air Waste Man. Ass. 42, 810-813.

Lai Y. K., Matisova E., He D., Singer E. and Niki H. (1993) Evaluation of capillary gas chromatography for the measurement of $\mathrm{C} 2-\mathrm{C} 10$ hydrocarbons in urban air samples for air pollution research. J. Chromat. 643, 77-90.

Lin C. and Milford J. B. (1993) Chemical mass balance modelling for volatile organic compounds. 93-TP-58.0 Air and Waste Management Association, 86th Ann. Meeting and Exhibition, Denver, Carolina.

National Research Council (1992) Rethinking the Ozone Problem in Urban and Regional Air Pollution. National Academy Press, Washington, District of Columbia.

Philpott P. (1993) User's Guide to MOBILE5C. Transportation Systems Division, Environment Canada, Ottawa, Canada.

Pierson W. R., Gertler A. W. and Bradow R. L. (1990) Comparison of the SCAQS tunnel study with other onroad vehicle emission data. J. Air Waste Man. Ass. 40, 1495-1504.

Radian Corporation (1992) Review of Air Toxics Emission Calculations from Storage Tanks: Phase I. API \# 2525, American Petroleum Institute, Washington, District of Columbia.

Robinson N. R., Pierson W. R. and Gertler A. W. (1993) Comparison of Real World CO, VOC, and $\mathrm{NO}_{x}$ Emission Rates with Motor Vehicle Emission Models. Regional 


\section{R. McLAREN et al}

Photochemical Measurement and Modelling Studies Specialty Conf., Air and Waste Management Association, San Diego, California, 8-12 November.

Siegl W. O., McCabe R. W., Chun W., Kaiser E. W., Perry J. Henig Y. I., Trinker F. H. and Anderson R. W. (1992) Speciated hydrocarbon emissions from the combustion of single component fuels I. Effect of fuel structure. $J$. Air Waste Man. Ass. 42, 912-920.

Sigsby J. E., Tejada S. and Ray W. (1987) Volatile organic compound emissions from 46 in-use passenger cars. Environ. Sci. Technol. 21, 466-475.

U.S. EPA (1991) User's Guide to MOBILE4.1: Mobile Source Emission Factor Model. EPA-AA-TEB-91-01, U.S. Environmental Protection Agency, Research Triangle Park, North Carolina.

U.S. EPA (1993) MOBILE5A Draft User's Guide. U.S. Environmental Protection Agency, Research Triangle Park, North Carolina.
Watson J. G., Robinson N. F., Chow J. C., Henry R. C Bongmann K., Nguyen Q. T., Meyer E. L. and Pace T. G. (1990) Receptor Model Technical Series, Vol III: CMB7 User's Manual. EPA-450/4-90-004, U.S. Environmental Protection Agency, Research Triangle Park, North Carolina.

Wittorff D. N., Gertler A. W., McLaren R. and Belzer W. (1994) Characterization of Vehicle Emissions in the Cassiar Tunnel, Vancouver B. C. Publication No. PMD 94-6, Environment Canada, Ottawa, Ontario.

Zwolinski B. J. and Wilhoit R. C. (1971) Handbook of Vapour Pressures and Heats of Vaporization of Hydrocarbons and Related Compounds. Publication 101, API44-TRC, American Petroleum Institute, Washington, District of Columbia. 